\title{
Potentiation of $\alpha$-Amino-3-hydroxy-5-methyl-4-isoxazole Propionic Acid (AMPA)-Selective Glutamate Receptor Function by a Nootropic Drug, Idebenone
}

\author{
Shunya Nakamura, Shuji KaneKo, and Masamichi SatoH* \\ Department of Pharmacology, Faculty of Pharmaceutical Sciences, Kyoto University, Yoshidashimoadachi-cho, \\ Sakyo-ku, Kyoto 606-01, Japan. Received June 10, 1993
}

\begin{abstract}
Effect of idebenone on the $\alpha$-amino-3-hydroxy-5-methyl-4-isoxazole propionic acid (AMPA)-selective glutamate receptor was evaluated using Xenopus oocytes injected with RNAs encoding mouse $\alpha 1$ and $\alpha 2$ AMPA receptors. Concanavalin A augmented current responses of the RNA-injected oocytes to glutamate, kainate, and AMPA and these responses were further potentiated by $100 \mu \mathrm{M}$ idebenone. The minimum concentration of idebenone that gave a significant potentiation was $10 \mu \mathrm{M}$ for glutamate. These results suggest that idebenone acts on AMPA-selective glutamate receptor channels composed of $\alpha 1$ and $\alpha 2$ subunits.
\end{abstract}

Keywords AMPA-selective glutamate receptor; Xenopus oocyte; idebenone; AMPA; kainate

Glutamate mediates a major excitatory synaptic transmission in many areas of the vertebrate central nervous system, ${ }^{1)}$ and appears to play a critical role in normal and pathological brain functions. ${ }^{2)}$ Glutamate receptors have been classified into three major subtypes; metabotropic, $N$-methyl-D-aspartate (NMDA), and nonNMDA subtypes on the basis of pharmacological and electrophysiological properties. Although the last subtype can be subdivided into kainate and $\alpha$-amino-3-hydroxy-5methyl-4-isoxazole propionic acid (AMPA) subtypes, it has been difficult to distinguish kainate and AMPA subtypes since there are no selective antagonists. However cDNA clones specific for the AMPA receptors subunits $(\alpha 1-\alpha 4$ derived from mice, corresponding to GluR1GluR4 or GluR-A - GluR-D in rats) have been isolated. Although these receptor subunits have been shown to respond to kainate as well as AMPA and quisqualate, they are referred to as AMPA-selective glutamate receptors since AMPA and quisqualate exhibit a higher apparent affinity for these receptors. ${ }^{3)}$

We have previously reported ${ }^{4)}$ that idebenone potentiates AMPA- and kainate-evoked current responses in Xenopus oocytes injected with guinea pig forebrain poly(A) ${ }^{+}$mRNA. The potentiating effect of idebenone was reversible and specific for the non-NMDA responses and no change was observed in the current responses mediating NMDA and metabotropic glutamate receptors. However, the site of idebenone action was unclear since the oocytes injected with brain mRNA can express a library of membranous and cytosolic proteins. Therefore, we have tried to investigate the mechanism of the AMPA-specific potentiation by idebenone using Xenopus oocytes expressing cloned AMPA-selective receptors.

\section{MATERIALS AND METHODS}

Oocyte Preparation Plasmid pSPGR1 and pSPGR2 carrying mouse $\alpha 1$ and $\alpha 2$ cDNAs, respectively, were generously provided by Professor Masayoshi Mishina (Department of Neuropharmacology, Brain Research Institute, Niigata University, Niigata, Japan). The cRNAs were synthesized by use of an mCAP ${ }^{\mathrm{TM}}$ mRNA Capping Kit (Stratagene, La Jolla, CA, U.S.A.). The capped RNAs were dissolved in ribonuclease (RNase)-free water at a concentration of $0.2 \mu \mathrm{g} / \mu \mathrm{l}$ and stored at $-80^{\circ} \mathrm{C}$ ). Female Xenopus laevis frogs (from JOFU, Chiba, Japan) were anesthetized in ice-cold water and pieces of the ovarian lobes were removed. To remove follicular layers from oocytes, the lobes were gently swirled at $20^{\circ} \mathrm{C}$ for 30 $90 \mathrm{~min}$ in a $100 \mathrm{ml}$ beaker with $30 \mathrm{ml}$ of sterile saline containing $0.8-1.0 \mathrm{mg} / \mathrm{ml}$ collagenase (Wako Pure Chemicals, Osaka, Japan or Sigma Chemical Co., St. Louis, MO, U.S.A.), $88 \mathrm{~mm} \mathrm{NaCl}, 1 \mathrm{~mm} \mathrm{KCl}, 1 \mathrm{~mm} \mathrm{MgSO}_{4}, 2.4 \mathrm{~mm}$ $\mathrm{NaHCO}_{3}, 7.5 \mathrm{~mm}$ Tris- $\mathrm{HCl}$ (pH 7.6). Large, healthylooking oocytes were selected and injected with $50 \mathrm{nl} /$ cell of a mixture of RNA solution (total $0.2 \mu \mathrm{g} / \mu \mathrm{l}, \alpha 1: \alpha 2=$ $1: 1)$. The oocytes were maintained at $20-23^{\circ} \mathrm{C}$ for several days in sterile modified Birth's solution $(88 \mathrm{mM} \mathrm{NaCl}, 1 \mathrm{mM}$ $\mathrm{KCl}, 0.41 \mathrm{~mm} \mathrm{CaCl}_{2}, 0.33 \mathrm{~mm} \mathrm{Ca}\left(\mathrm{NO}_{3}\right)_{2}, 0.82 \mathrm{mM} \mathrm{MgSO}_{4}$, $2.4 \mathrm{~mm} \mathrm{NaHCO}, 3.5 \mathrm{~mm}$ Tris- $\mathrm{HCl}(\mathrm{pH} 7.6), 10 \mu \mathrm{U} / \mathrm{ml}$ penicillin and $10 \mu \mathrm{g} / \mathrm{ml}$ streptomycin). To increase their viability, in some experiments, oocytes were incubated for $24 \mathrm{~h}$ after injection in a Birth's solution supplemented with $5 \%$ horse serum (GIBCO, BRL, U.S.A). ${ }^{5)}$

Electrophysiological Measurement An oocyte was placed in a $50 \mu \mathrm{l}$ chamber perfused continuously at a flow rate of $0.8-1.5 \mathrm{ml} / \mathrm{min}$ with frog Ringer solution containing $115 \mathrm{~mm} \mathrm{NaCl}, 2.5 \mathrm{mM} \mathrm{KCl}, 1.8 \mathrm{mM} \mathrm{CaCl}_{2}$, $10 \mathrm{~mm}$ HEPES-NaOH (pH 7.4). The temperature of the recording solution was maintained at $20-23^{\circ} \mathrm{C}$. The oocyte was impaled on two glass electrodes filled with $3 \mathrm{M}$ $\mathrm{KCl}$ (for voltage monitoring) and $3 \mathrm{M}$ potassium acetate (for current injection), respectively, and clamped at a holding potential of $-70 \mathrm{mV}$. The cellular responses of oocytes to drugs were identified by the whole-cell ionic current flowing through the virtual ground line of a voltage-clamp amplifier (Nihon Kohden CEZ-1200, Kyoto, Japan).

Drug Application L-Glutamate (Wako, Osaka, Japan), kainate and AMPA (Nacalai Tesque, Kyoto, Japan) were dissolved in the recoding solution and applied by switching the perfusion line. Idebenone was a gift from Takeda 
Chemical Industry (Osaka Japan), which was dissolved in dimethylsulfoxide (DMSO) at a concentration of $0.1 \mathrm{mM}$ and then diluted with the recording solution. DMSO in itself did not evoke any current response at the final concentrations (less than $0.1 \%$ ) nor did it affect agonist-induced currents in the cRNA-injected oocytes. One of the agonists was applied to an oocyte twice at intervals of $4-5 \mathrm{~min}$. The first: control (agonist alone); the second: agonist together with idebenone following $2 \mathrm{~min}$ perfusion with idebenone alone. When oocytes were treated with Concanavaline A (Con A, Sigma, typeIV), it was dissolved in the recording solution and perfused for $5 \mathrm{~min}$ before the oocyte received the first application of agonist.

Statistics Results were expressed as means \pm S.E.M. of $4-9$ experiments. Statistical significance was evaluated by either Student's $t$-test or the Mann-Whitney $U$-test.

\section{RESULTS}

The effects of idenbenone on AMPA-selective glutamate receptors were examined using Xenopus oocytes injected with a mixture of RNAs complementary to $\alpha 1$ and $\alpha 2$
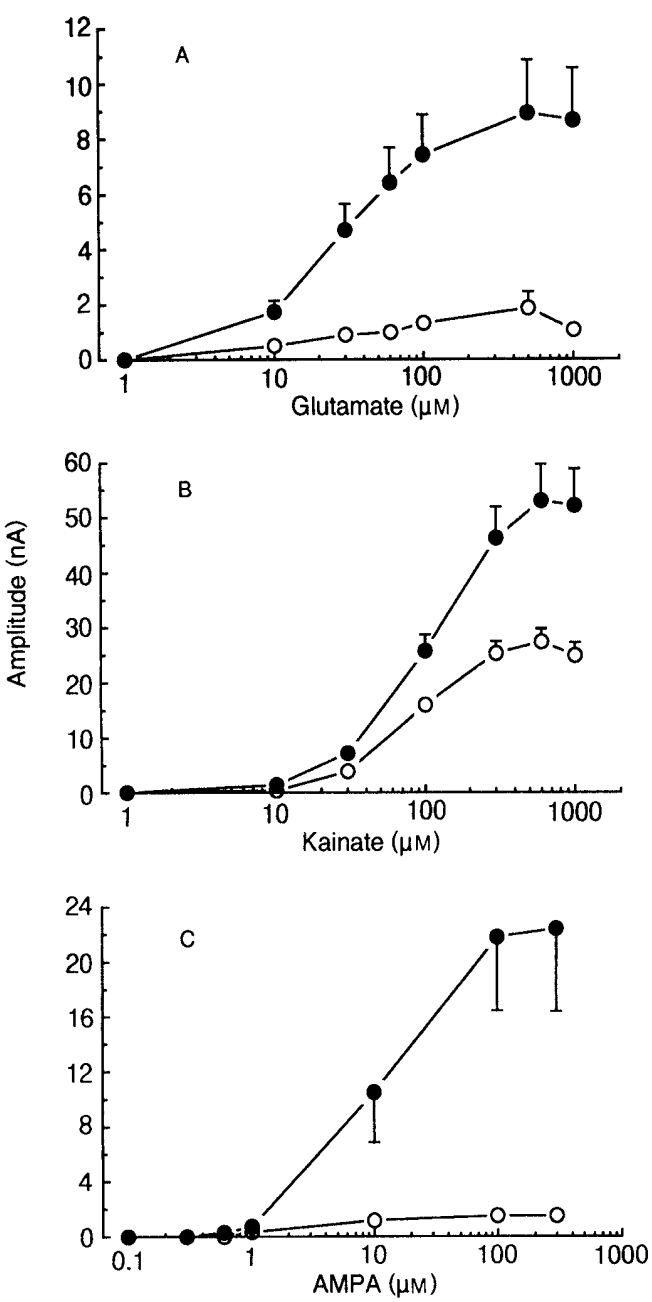

Fig. 1. Effects of Con A on Current Responses to Glutamate, Kainate, and AMPA in Xenopus Oocytes $3 \mathrm{~d}$ after Injection with a Mixture of Mouse AMPA Receptor $\alpha 1 / \alpha 2$ cRNAs

Graphs indicate peak amplitudes of current responses to glutamate (A), kainate (B), and AMPA (C) in the oocytes without (open circle) and with (closed circle) $2.5 \mu \mathrm{M}$ Con A treatment. Each point represents the mean \pm S.E.M. of the amplitude obtained from $3-6$ oocytes at $-70 \mathrm{mV}$.
cDNAs clones. After incubation for $3 \mathrm{~d}$, current responses to glutamate receptor agonists were detected in the injected oocytes. After perfusion with $2.5 \mu \mathrm{M}$ Con A for $5 \mathrm{~min}$, before application of the agonists, the oocytes exhibited $4.9,1.9,14.9$-fold increase in the maximum amplitude of glutamate, kainate, and AMPA responses, respectively (Fig. 1A, B, C). In these cases, however, the concentrations of glutamate required to produce half-maximum activation $\left(\mathrm{EC}_{50}\right)$ were similar in the untreated $(25.4 \mu \mathrm{M})$ and Con A-treated oocytes $(27.4 \mu \mathrm{M})$. No current responses to these agonists were detected in RNA-non-injected oocytes either without or after Con $\mathrm{A}$ treatment. The $\mathrm{EC}_{50}$ values for kainate were 79.8 and $94.4 \mu \mathrm{M}$ in the untreated and Con A-treated groups, respectively. These responses were completely antagonized by $10 \mu \mathrm{M}$ 6-cyano-7-nitroquinoxaline-2,3-dione (CNQX) (data not shown).

Figure 2 shows representative current responses of the cRNA-injected, Con A-treated, oocytes evoked by $100 \mu \mathrm{M}$ glutamate, $100 \mu \mathrm{M}$ kainate, and $10 \mu \mathrm{M}$ AMPA in the presence and absence of $100 \mu \mathrm{M}$ idebenone. In these cases, we applied concentrations of agonists required to produce control

A glutamate $(100 \mu \mathrm{M})$

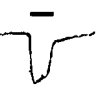

B kainate $(100 \mu \mathrm{M})$

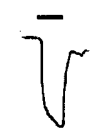

C $\operatorname{AMPA}(10 \mu \mathrm{M})$
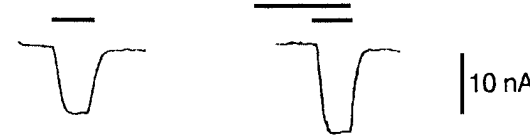
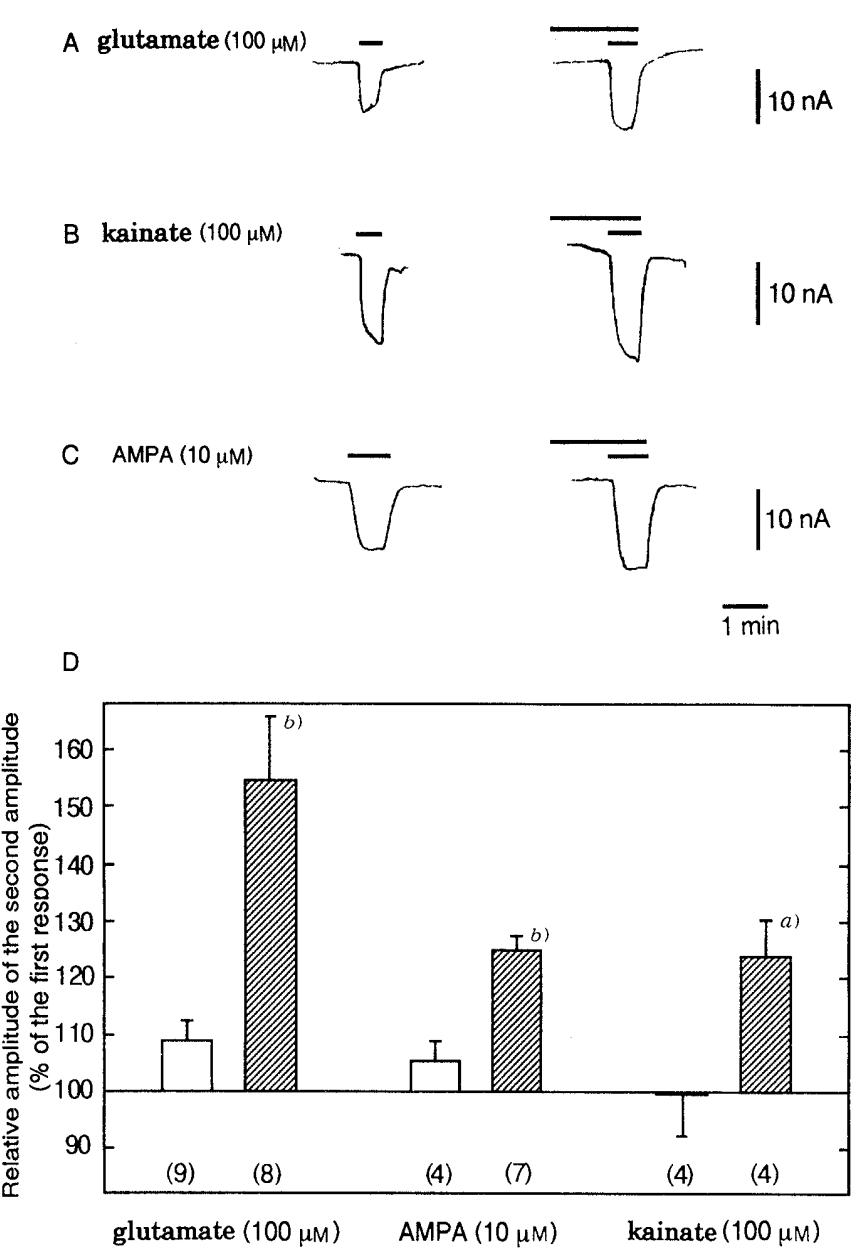

Fig. 2. Effects of Idebenone on Glutamate, Kainate, AMPA-Evoked Currents in $\alpha 1 / \alpha 2$ cRNA-Injected and Con A-Treated Oocytes

The oocytes were clamped at $-70 \mathrm{mV}$ and activated with agonist twice, before and during idebenone or vehicle perfusion; the first: control (agonist alone), the second: agonist together with idebenone. A, B, C: whole-cell currents evoked by bath-application of $100 \mu \mathrm{M}$ glutamate (A), $100 \mu \mathrm{M}$ kainate (B), and $10 \mu \mathrm{M}$ AMPA (C) before and during perfusion with $100 \mu \mathrm{M}$ idebenone. D: potentiating effects of idebenone are shown as \% of the amplitude of the first response to agonists. Open and hatched bars indicate vehicle and idebenone-treated groups, respectively. $a, b) p<0.05,0.01$ vs. vehicle group, respectively. 


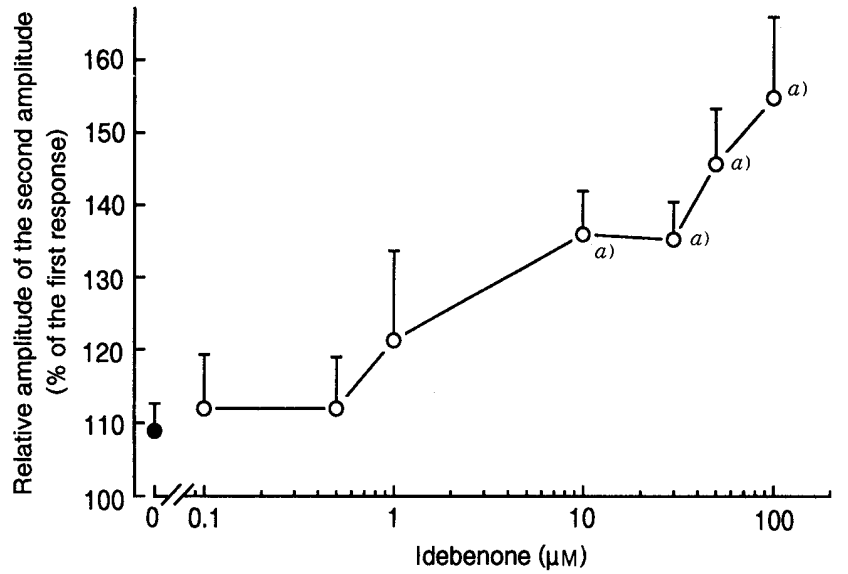

Fig. 3. Concentration-Dependence of Potentiating Effect of Idebenone on the Glutamate $(100 \mu \mathrm{M})$-Evoked Response of Oocytes Injected with $\alpha 1 / \alpha 2$ cRNAs and Treated with Con A

Each point represents the mean \pm S.E.M. of $\%$ of control values obtained from $4-9$ oocytes. a) $p<0.01$ vs. dose 0 .

half-maximum activations. In control oocytes treated with vehicle $(0.1 \%$ DMSO) solution, the second amplitude was $109 \pm 3 \% \quad(n=8)$ of the first response. Treatment with $100 \mu \mathrm{M}$ idebenone increased the amplitude of the second glutamate response to $155 \pm 11 \% \quad(n=9)$ of the first response $(p<0.01$, Fig. 2D). Comparing the relative amplitudes in untreated oocytes and in idebenone-treated oocytes, those of AMPA-evoked currents were $105 \pm 3 \%$ $(n=4)$ and $125 \pm 2 \%(p<0.01, n=7)$, respectively, and those of kainate-evoked currents were $99.7 \pm 8 \%(n=4)$ and $124 \pm 6 \%(p<0.05, n=4)$, respectively. Furthermore, idebenone also potentiated glutamate-evoked currents significantly without Con A treatment of the injected oocytes $(95.9 \pm 8 \%$ in vehicle group, $n=3$ and $134 \pm 10 \%$ in idebenone-treated group, $p<0.05, n=5$, respectively).

The potentiating effect of idebenone on glutamate response was dose-dependent and a significant potentiation was observed at a concentration of $10 \mu \mathrm{M}$ or more (Fig. 3). The highest, but not-saturated, effect of idebenone was obtained at $100 \mu \mathrm{M}$, since idebenone could not be dissolved completely in the recording solution above this concentration.

\section{DISCUSSION}

Xenopus oocytes injected with RNA encoding $\alpha 1$ and $\alpha 2$ subunits acquired responsiveness to glutamate and kainate, which was detectable by voltage clamp recording. However, AMPA-evoked current was hard to record in the clone RNA-injected oocytes without Con A treatment. Since AMPA $(10 \mu \mathrm{M})$-evoked responses were easily detectable in oocytes injected with brain poly $(\mathrm{A})^{+}$RNA with an average amplitude of several $\mathrm{nA}$ at $-60 \mathrm{mV}$, the amount of expression of cloned AMPA receptors was rather lower than expected. Although the reason cannot be specified, such a low-expression may reflect insufficient stability of synthesized RNA in the oocytes, which is primarily defined by the sequence and structure of the non-coding region of RNA. ${ }^{6}$ Another possible reason is that to express the full function of the AMPA receptor, other subunits or proteins may be required that can modulate AMPA receptor responses. However, other groups have detected AMPA- or quisqualate-evoked current responses in cRNA-injected oocytes similar to those in poly $(\mathrm{A})^{+}$RNA injected oocytes, thought in both cases the responses to AMPA $(50 \mu \mathrm{M})$ or quisqualate $(1-50 \mu \mathrm{M})$ were less than $10 \%$ of the responses to $100 \mu \mathrm{M}$ kainate. ${ }^{3)}$ In view of this point, it seems that the former reason is more likely.

Considering that these responses were completely antagonized by $10 \mu \mathrm{M}$ CNQX, and a single injection of $\alpha 1$ or $\alpha 2$ RNA produced much smaller oocyte responses to these agonists (data not shown), the glutamate agonistevoked current responses of oocytes expressing $\alpha 1 / \alpha 2$ proteins exhibited the functional properties of, so-called, AMPA-selective glutamate receptors that have been reported previously. ${ }^{3 a)}$ The efficacy, but not affinity, of agonists in evoking the current responses were irreversibly potentiated by pretreatment of the oocytes with Con A, which has been reported to reduce desensitization of ionotropic quisqualate receptors in mouse embryonic hippocampal neurons and glutamate receptors in rat dorsal root ganglion neurons. ${ }^{7)}$ The Con A-induced potentiation was apparent in the glutamate and AMPA responses and there was only about a 2-fold increase in kainate response, which is in agreement with the observation in rat dorsal root ganglion neurons. ${ }^{7 a}$ Previous studies have shown that Con A selectively inhibited rapid desensitization of channel opening immediately after AMPA binding. ${ }^{7 b)}$ The current responses that we recorded correspond to the steady-state responses of AMPA-gated channels after the readilydesensitizing (mean time constant $=30 \mathrm{~ms})^{7 b}$ current since it took several seconds to replace the perfusing solution in the recording chamber.

As a mode of action of idebenone, although it has been demonstrated that idebenone improved brain energy metabolism and inhibited lipid peroxidation in brain mitochondria, ${ }^{8)}$ the present observation that the glutamate agonist-evoked current responses in the oocytes expressing $\alpha 1 / \alpha 2$ proteins were potentiated by idebenone indicates that the AMPA-selective glutamate receptors also participate in idebenone action. The increase in the amplitude of glutamate-evoked responses was, however, similar in the Con A-treated and untreated oocytes, suggesting that the mechanisms underlying the potentiation by Con A and idebenone differ.

The results of the present study are not in good agreement with those from Xenopus oocytes injected with guinea pig brain poly $(\mathrm{A})^{+}$mRNA. The degree of potentiation of AMPA response by idebenone in the oocytes injected with cRNAs was smaller than that in the oocytes injected with poly(A) ${ }^{+}$mRNA, compared with the kainate response data. Idebenone may require factors other than $\alpha 1$ and $\alpha 2$ subunits to potentiate AMPA response.

The minimum concentration of idebenone needed to elicit a significant increase in the glutamate-evoked response was $10 \mu \mathrm{M}$. Since it is apparently higher than the presumed plasma concentration of the drug, the glutamate-potentiating effect of idebenone seems not to be involved in the nootropic action of this compound. However, the concenration of idebenone required to 
increase AMPA-related responses was lower than that of aniracetam which is reported to act allosterically on AMPA receptors. ${ }^{9)}$ Aniracetam showed agonist-dependent potentiation of an AMPA/kainate receptor composed of GluR 1/GluR2 subunits. ${ }^{9 a}$ ) Regarding a mechanism, it is supposed that aniracetam potentiates the steady-state current responses by reducing the desensitization as described above. However the detailed mechanism of action of aniracetam is still unknown. Idebenone may also possibly potentiate steady-state current responses by reducing the desensitization. Since the chemical structures of these agents are quite different, however, more studies are required to clarify the modulation mechanism of AMPA-selective glutamate receptor/channel molecules.

Acknowledgment We thank Professor Masayoshi Mishina for providing us with pSPGR1 and pSPGR2.

\section{REFERENCES}

1) D. T. Monaghan, R. J. Bridges, C. W. Cotman, Annu. Rev. Pharmacol. Toxicol., 29, 365 (1989).

2) D. V. Madison, R. C. Malenka, R. A. Nicoll, Annu. Rev. Neurosci.,
14, 379 (1991); B. Meldrum, J. Garthwaite, Trends Neurosci., 11, 379 (1990).

3) a) K. Sakimura, H. Bujo, E. Kushiya, K. Araki, M. Yamazaki, M. Yamazaki, H. Meguro, A. Warashina, S. Numa, M. Mishima, FEBS Lett., 272, 73 (1990); b) J. Boulter, M. Hollmann, A. O'Shea-Greenfield, M. Hartley, E. Deneris, C. Maron, S. Heinemann, Science, 249, 1033 (1990); c) K. Keinänen, W. Wisden, B. Sommer, P. Werner, A. Herb, T. A. Verdoorn, B. Sakmann, P. H. Seeburg, ibid., 249, 556 (1990).

4) S. Kaneko, M. Sugimura, T. Inoue, M. Satoh, Eur. J. Pharmacol., 207, 119 (1991).

5) M. W. Quick, J. Naeve, N. Davidson, H. A. Lester, Biotechniques, 13, 357 (1992).

6) A. Annweiler, R. A. Hipskind, T. Wirth, Nucleic Acids Res., 19, 3750 (1991); D. R. Drummond, M. A. McCrae, A. Colman, J. Cell Biol., 100, 1148 (1985); G. Galili, E. E. Kawata, L. D. Smith, B. A. Larkins, J. Biol. Chem., 263, 5764 (1988).

7) a) J. E. Huettner, Neuron, 5, 255 (1990); b) M. L. Mayer, L. Vyklicky, Jr., Proc. Natl. Acad. Sci. U.S.A., 86, 1411 (1989); c) L. L. Thio, D. B. Clifford, C. F. Zorumski, Neuroscience, 52, 35(1993).

8) M. Suno, A. Nagaoka, Biochem. Biophys. Res. Commun., 125, 1046 (1984); A. Nagaoka, M. Suno, M. Shibata, M. Kakihana, Nippon Yakurigaku Zasshi., 84, 303 (1984).

9) a) K. Tsuzuki, T. Takeuchi, S. Ozawa, Mol. Brain. Res., 16, 105 (1992); b) I. Itoh, S. Tanabe, A. Kohda, H. Sugiyama, J. Physiol. (London), 424, 533 (1990). 